\title{
INFORMATION AND COMMUNICATION TECHNOLOGY (ICT) INEQUITIES: A COMPARATIVE LITERATURE REVIEW OF EDUCATION IN THE UNITED STATES AND LIBERIA
}

\author{
Damita Kaloostian $^{1}$ and Nalini Chhetri ${ }^{2}$ \\ ${ }^{1}$ School for the Future of Innovation in Society, College of Global Futures, \\ Arizona State University, Tempe, USA \\ ${ }^{2}$ School for the Future of Innovation in Society \& School of Sustainability, \\ College of Global Futures, Arizona State University, Tempe, USA
}

\begin{abstract}
Globally, the potential of ICT has resulted in mass deployment, transforming the educational landscape in accordance with 21st-century demands. The diffusion of ICT within education has shown tremendous benefits, positively impacting students and teachers in learning, instruction, engagement, and assessment $(\mathrm{Fu}, 2013)$. However, the widespread application of technology to address education access and quality has not been universally adopted for various reasons, resulting in the exclusion of critical segments of the world's population. As a result of the current technology inequities, the current literature review focuses on access to and use of ICT within education. More specifically, it seeks to explore: What does the comparative and international research say regarding the factors that facilitate access to and use of ICT among underserved $K-8$ education populations in the United States and Liberia?
\end{abstract}

\section{KEYWORDS}

Digital divide, Digital inequities, United States, Liberia, ICT, Education, Technology.

\section{INTRODUCTION}

\subsection{The Global Education Challenge}

According to the 2020 United Nations report [1], approximately 262 million children are not enrolled in schools, and more than 617 million students lack essential reading and math skills. For decades, the staggering number of children without access to formal education coupled with poor academic learning outcomes of those enrolled in schools have attracted global attention. This concern has been key in leveraging educational frameworks that align with the Sustainable Development Goals (SDGs) \# 4 - to ensure inclusive and equitable quality education- which has emerged to unify countries and their corresponding efforts to deliver quality education. With the global focus on education access and quality established, Information and Communication Technology (ICT) has emerged as a pivotal platform to support quality teaching, learning, and student achievement. Globally, the potential of ICT has resulted in mass deployment to transform the educational landscape in accordance with $21^{\text {st- }}$ century demands that require diverse types of educated individuals. 
The diffusion of ICT within the education system has shown tremendous benefits, positively impacting students and teachers in learning, instruction, engagement, and assessment [2]. However, the widespread application of technology to address education access and quality has not been universally adopted and disseminated, resulting in the exclusion of critical segments of the world's population. In addition, the inherent nature of technology is fast-paced and ever-evolving. This pace has resulted in a constant struggle for many countries to not only "catch up" but to "keep up" with the rapidly changing technological environment. Currently, billions of individuals, especially students, without internet and ICT access serve as a reminder to the world of the need to think differently about how technology is accessed, utilized, and applied, particularly within the educational landscape. The consequences of not addressing this critical global challenge are significant and risk millions to be further marginalized.

\section{FrameWORK}

\subsection{Overview}

This literature review focuses on access to and use of ICT in education within the context of current technology inequities. More specifically, it seeks to explore comparative and international research on factors facilitating access to and use of ICT among underserved K-8 educated populations in the United States and Liberia. The selection of the United States and Liberia was intentional to explore the research question within the context of developed and developing geographic locations. Each country was selected as a representative of these regions to illustrate its unique experiences as well as identify areas of similarities. The selection of the United States and Liberia is appropriate for this comparative literature review as both countries' educational structures are similar due to the historical creation and settlement of Liberia by the United States and religious groups of its freed slaves [3]. The current literature review examines the research question from a holistic perspective and considers the varying levels of education-related ICT adoption and integration by both countries. Ultimately, this review seeks to provide insights related to technology integration that has improved or has the potential to improve the overall quality of education in the United States and Liberia.

\subsection{Bray \& Thomas Comparative Perspective}

This literature review will leverage the Bray \& Thomas [4] framework for comparative education to include geographic/location levels (country), non-locational demographics (K-8 Schools), and aspects of society (factors facilitating ICT access for underserved populations) (see Table 1). These identified areas of exploration are key to this review as they represent fundamental factors that are likely to improve the global outcomes related to education. The literature review compares these two countries and uses context at micro and macro levels to address the research question.

Table 1.Bray \& Thomas Framework

\begin{tabular}{|l|l|l|}
\hline Dimension & Level & Research Focus \\
\hline Geographic/Locational & Country & United States and Liberia \\
\hline Nonlocational Demographic & K-8 Schools & $\begin{array}{l}\text { Gender, Ethnicity, Socioeconomic, } \\
\text { Location }\end{array}$ \\
\hline Aspects of Education/Society & Academic Institutions & ICT Access and Use \\
\hline
\end{tabular}




\section{Context}

\subsection{ICT \& Education}

The concept of ICT is defined as "a broad term that includes computers, the internet, and electronic delivery systems such as radios, televisions, and projectors, among others, and is widely used in today's education field" [2, p. 112]. Expanding upon this definition, Kumar [5] suggests that ICT represents an overarching framework that includes "cellular phones, computers, and network hardware and software, satellite systems and so on, as well as the various services and applications associated with them, such as videoconferencing and distance learning" (p. 1). While this definition is well-established, it is essential to note that the definition is continuously evolving due to the everchanging technological environment.

Over the last few decades, ICT has changed the educational landscape in significant ways. The role of technology within education has become so prevalent that it is often difficult to separate learning from its technological influences. The growing popularity of the internet and its corresponding financial investment have fueled the adoption and implementation of ICT within the education sphere. Escueta et al. [6] note that "in the United States, the market for PreK-12 software alone had exceeded $\$ 8$ billion, and a recent industry report projects an estimated value of $\$ 252$ billion for the global ed-tech industry by $2020 "$ (p. 2). In Liberia, a country of 5 million people, financial investment projections suggest that approximately $\$ 432$ million is needed to increase internet access from the current level (19\%) to $90 \%$ by 2030 [7].

In general, countries with the human and financial resources to leverage ICT have done so at astounding rates with demonstrated benefits in many key areas of the education system. ICT benefits in education are varied and include expanded access, enhanced flexibility, and optimized learning environments. Improved learning outcomes are also evidence of the benefits of technology. De Witte and Rogge [8] identify improvements in student learning and school costs as critical benefits. Researching ICT within mathematics, the authors note that technology promotes "greater flexibility and autonomy for pupils in their learning and the learning attitudes and experiences of pupils" [8, p. 174]. Also, "research has indicated that technology can increase student motivation, attitude, engagement, and self-confidence while improving organization and study skills" [9, p. 110].

Research also shows that student improvement in technology skills and analyzing complex problems are vital benefits of ICT in education [10]. Electronic books (eBooks) are another benefit of technology and education. This resource provides cost efficiency, expanded access, and dynamic learning experiences as students can take notes and highlight essential information without damaging traditional textbooks [11]. Perrotta [12] examined the benefits of ICT in the classroom through survey research and noted that nearly 90 percent of participating teachers indicated that technology provided some added value to the education experience. Of the teachers reporting ICT benefits, expanded access to learning content and resource materials were the most cited enhancement to education [12].

\subsection{The Emerging Divide}

The benefits of technology in realizing global education goals are evident, yet ICT within the academic landscape has also created inequities in access, use, engagement, and empowerment. With regard to ICT integration, the more resource advantaged populations gained momentum using ICT, while resource disadvantaged populations were unable to leverage technology at a similar rate. Even as ICT access and use were expanded, marginalized groups were not equitable 
recipients of this expansion [13]. The skills and resources that are cultivated through the use of ICT were also disproportionately leveraged, creating larger disparities for these same populations. Ultimately, the intersections of ICT, education, and technology inequities have created both shortterm and far-reaching implications that represent one of the most critical endeavors to improved quality education.

Examining ICT within the scope of this literature review requires an understanding of technology inequities. These technology inequities are referred to as the digital divide or digital inequities, which is defined as the gap between those who do and those who do not have access to and adequate knowledge of ICT [14]. These forms of technology often include computers and their networks. Other digital technologies such as mobile phones and televisions are also considered when discussing the digital divide [15]. Recognizing the complexities of the digital divide, Hohlfeld et al. [16] identify three key levels when conducting research : (1) school infrastructure,

(2) classroom, and (3) individual students (see Figure 1).

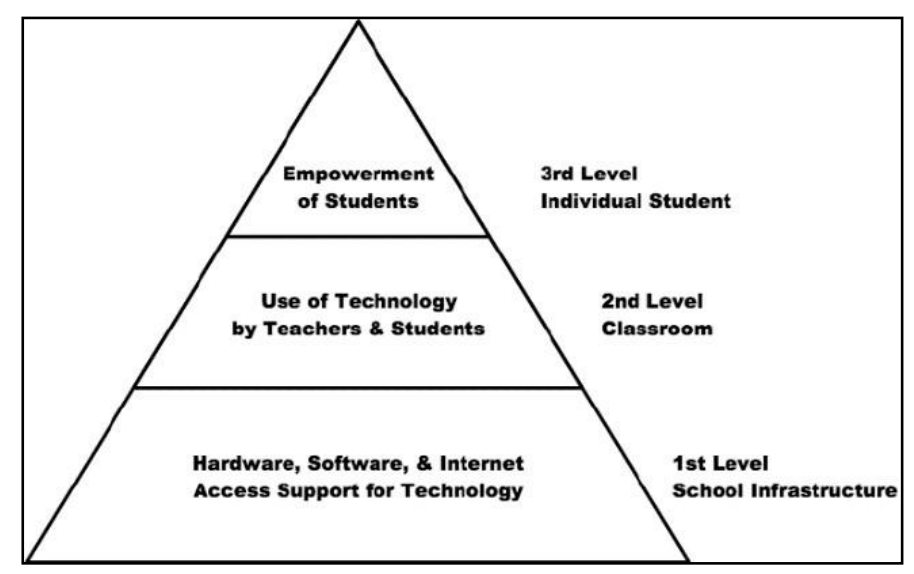

Figure 1. Source: "Levels of Digital Divide," Hohlfeld et al. [16].

Research regarding the first-level digital divide focuses on topics related to access and infrastructure. Selwyn [17] notes that these ICT inequities are perpetuated for learners through the use of older equipment, limited knowledge of technology platforms, and lack of technology skills when discussing the first-level digital divide. Additional research documenting the magnitude of the first level digital divide suggests that "while 98 percent of children in United States households with incomes exceeding $\$ 100,000$ per year have a computer at home, only 67 percent of children in households with incomes lower than $\$ 25,000$ have them"[6, p. 3]. In contrast, access to ICT is minimal in Liberia, where limited energy sources such as electricity have resulted in only a very small percentage of the population having access to the internet [18]. The limited ICT availability, including internet access, poses a fundamental challenge in addressing the first-level digital divide in Liberia and the United States.

According to Reinhart, Thomas, \& Toriskie [19], the second-level digital divide (SLDD) "is no longer a simple delineation between those who have access to technology and those who do not. SLDD refers to the difference in how technology is utilized" (p. 181). Osborne \& Morgan [20] explored the second-level digital divide and found that teachers in low-income areas are less likely to use technology resources effectively than teachers in more affluent areas. Research on these inequalities notes that individuals from low-socioeconomic backgrounds may use technology for social and entertainment purposes, which potentially limits the development of key skills necessary for academic and professional success [20]. While researching the second-level digital divide, Escueta et al. [6] note that providing access to technology must be accompanied by adequate technical guidance to address the digital use divide. 
Van Deursen and Helsper [21] suggest that "the third-level digital divide concerns disparities in the returns from internet use within populations of users who exhibit broadly similar usage profiles and enjoy relatively autonomous and unfettered access to ICTs and the internet infrastructure" (p. 30). An important finding in this exploratory research is that although more people have access to the internet, this resource disproportionately benefits those with a higher social status. This finding is not surprising but insightful as it suggests that resources designed to mitigate inequalities may be perpetuating these disparities in new and unknown ways.

It is also essential to understand who is impacted by the digital divide. The progress of ICT in education has inadvertently cultivated education inequities, impacting populations based on gender, ethnicity, socioeconomic status, and geography [22]. Providing context to gender as an underserved population, Wanyonyi [23] notes that some cultural norms place greater importance on educating boys resulting in education and ICT disparities for large populations of girls. Socioeconomic status is also a critical factor in defining underserved populations, with students from low-income households experiencing more challenges to digital inclusion, particularly in computer and internet access in the home [24]. Wanyonyi [23] notes that the traditional definition, which includes areas farther away from cities with lower populations, should also be expanded to concentrated areas of low populations when discussing geography and underserved populations. The digital divide research also identifies ethnic minorities such as Blacks and Latinos as having unequal access to computers and ICT-related resources [25].

\section{SignificAnCE}

\subsection{Global Importance}

Closing the ICT gap for underserved populations will be instrumental to achieving the Sustainable Development Goals (SDGs), particularly Goal \#4. Not only will ICT play a critical role in the achievement of the SDGs, but ICT has the potential to substantially fast-track the rate at which these global goals are actualized. The significance of an accelerated pace in achieving the SDGs suggests that larger segments of the population will have access to quality education that is enhanced by the benefits that ICT provides. Therefore, a larger portion of the population will be educated with the necessary knowledge and skills to improve individual conditions in key areas such as human capabilities, poverty alleviation, and economic development. At the core of this implication is the idea that expanded ICT access and use for underserved populations can create more equitable opportunities for individuals, fostering more significant opportunities to impact the world in meaningful and sustainable ways.

\subsection{Theoretical Relevance}

The literature review's significance is supported by theoretical frameworks that include human capital and the human development and capabilities approach. The human capital theory views education as an investment in the individual to improve the economy. Education is viewed as an investment in the individual, which is measured through factors such as productivity and earned wages [26]. Building upon the theoretical linkages between education and economics, advantages of education include greater employability and access to high-skilled jobs [27]. From this perspective, addressing the inequities in education and technology are significant due to the impact on the individual, local, national, and global economies. The human development and capabilities approach strongly supports the role of education within countries. By focusing on the individual and improving their capabilities, this framework offers a more streamlined pathway to the essential elements required for a quality life. The fundamental elements within these frameworks include freedom, empowerment, choice, and human dignity, all of which underline the essence of quality 
International Journal of Education (IJE) Vol.9, No.2, June 2021

education. It is important to note that this approach does not exclude economics as an area of emphasis. Rather, this framework provides a more holistic view of education, including the multidimensional factors that are key to transforming both people and countries.

\section{Problem Statement}

The proliferation of ICT has resulted in an unprecedented increase in access for students at home and in the classroom [28]. Without question, the widespread availability of technology provides considerable benefit to those in a position to leverage this important resource. Nearly 2.9 billion individuals have access to the internet, and a substantial amount of these users are school-aged students [28]. However, there is a growing concern for those individuals who are not afforded the same opportunities that ICT access provides [29]. Despite widespread access and use, ICT has asserted influence on different populations in very different ways, resulting in digital divides and digital inequities.

In 2019, approximately $86 \%$ of developed nations had internet access compared to $19 \%$ in developing countries [30]. In addition, estimates indicate that approximately half of the students (826 million) impacted by COVID-19 do not have computer technology within their homes, and 706 million (43\%) do not have internet access during a time where these resources are essential to continued learning [31]. The digital divide exists within countries with clear delineations occurring based on factors such as location, gender, ethnicity, and socioeconomic status. This divide is further perpetuated by access, cost, and reliability of broadband resources [32]. Technology has been increasingly deployed as a critical solution to address issues of inequity within education. However, decision-makers have failed to consider the new inequities cultivated through technology gaps, further expanding the divide in education and educational systems.

There has been considerable research conducted related to ICT, education, and the digital divide. Collectively, this literature provides insights into the unintended consequences of technology, particularly for marginalized populations, and argues that both access to and use of technology represent essential considerations when deciding to deploy this resource to support education. Currently, much of the digital divide literature explores this phenomenon at the micro-level, which means a specific group or initiative is explored. This literature review seeks to address this gap by exploring the topic using multidimensional foci. As such, the current literature review is situated at the nexus of the inequities in education technology access and use for underserved populations.

\section{Organizational Structure}

The organizational structure of the literature review leverages the body of knowledge from comparative education and global development as the core academic disciplines. Using a thematic literature review approach, the topic includes the United States and Liberia as two local examples of a global issue. It provides a detailed overview of the current international and comparative research related to ICT access and use among underserved populations for both countries. The literature review is leveraged to develop preliminary conclusions and themes regarding factors addressing the current research question. The review then discusses and analyzes the emerging central themes and uses this information to identify implications for education within local and global contexts.

\subsection{Literature Review Boundaries}

Kennedy [33] provides beneficial insights to frame the collection of information for a literature search. First, the topic search leverages at least one qualification and one indicator. This search's qualification is that the articles must be related explicitly to ICT inequities for one or more impacted groups (location, gender, race, socioeconomic status). More specifically, the qualifications focus 
primarily on the factors that impact access to and use of ICT for underserved populations. The qualifications also include the outcomes of such studies on the impacted groups. In addition, the indicators for this search include ICT development, implementation, assessment, and effectiveness. Modeling the recommendations of Kennedy [33], studies that focus on any of these areas meets the inclusion criteria. The literature search is limited to articles targeting the United States and Liberia to establish geographical boundaries. Currently, the study also focuses on articles from 2000-2020. However, literature outside this date range was analyzed to establish core concepts related to the topic. This range was intentional to better reflect the technological advances that have occurred within the last decade and to include the historical aspects that have shaped the global digital divide within the last two decades in education.

For the literature review, Google Scholar, Google, Education Resources Information Center (ERIC), and the Arizona State University Library Database were used. In ERIC, the keyword searches included "digital technology," "educational technology," "information technology," AND "primary education" OR "elementary education," AND "equal education" OR disadvantaged. In Google Scholar, the keyword search included "digital technology," "primary education," OR "elementary education," "equal education," OR "underserved." In addition, the exact keyword search was leveraged using Google to provide action-based research from organizations such as the United Nations Educational, Scientific and Cultural Organization (UNESCO) and Organization for Economic Co-operation and Development (OECD). For each database and keyword search, the lists of potential articles were documented.

The current research examined 97 articles for possible inclusion in the literature review. Ultimately 61 articles were included in the literature review as context or research studies. Articles were eliminated if they did not meet the original search criteria or were not formal research studies. Collectively, these boundary protocols created a systemic process for identifying and organizing the content. The process also helped to generate high-quality studies from peer-reviewed journal sources and reports from credible organizations within comparative education, technology, and global development.

\section{LiterATURE REVIEW}

\subsection{Infrastructure \& ICT- United States}

Establishing an adequate education infrastructure is paramount to quality teaching and learning. The research focusing on infrastructure as a fundamental factor in facilitating access to and use of ICT also includes the need for hardware, software and places particular focus on reliable internet connectivity. Expanding upon this framework, Warschauer \& Matuchniak [34] add individual knowledge of technology to the infrastructure framework, underscoring the important role teachers and technology support staff contribute to ICT in education.

Access to and use of ICT by underserved populations is primarily conditioned upon the quality infrastructure available to support education technology. There are currently widespread efforts in both the United States and Liberia to better integrate ICT into K-8 schools with a concerted effort in underserved populations. Despite the critical importance of infrastructure in facilitating 
access to and use of ICT for underserved populations, current literature indicates challenges in providing adequate ICT infrastructure for the United States. Two broad categories of infrastructure challenges include: (1) ICT-related deficiencies, which include computers, laptops, hardware, software, and the internet; and (2) structural-related challenges, which include factors such as physical buildings, furniture, and energy supply such as electricity. These two areas collectively represent the focus and framework for the infrastructure discussion in this literature review.

Within the United States, the infrastructure challenges are evidenced by the work of Warschauer et al. [10], who examined the integration of one-to-one laptop programs focusing on English Language Learners (ELLs), minorities, and low socioeconomic households through three geographically diverse case studies. Demonstrating the promise of ICT for underserved populations, the laptop integration program's results indicate higher levels of technology use for ELLs, Hispanics, and students receiving free or reduced-fee lunch, the latter an indicator of low socioeconomic status. In the third case study location, which had a high concentration of African American students, the laptop program showed increased computer and internet use and improved self-perceptions of technology proficiency. However, the study notes infrastructure-related challenges such as costs related to ICT purchases, technology maintenance as key determinants of such program's overall performance.

Providing additional evidence that expanded access and use of ICT for underserved populations depends on quality infrastructure, Mckenna [35] shows the promise of ICT use among rural students in the United States by exploring an ICT intervention project where iPads were deployed to $1^{\text {st }}$ and $2^{\text {nd }}$-grade students. For both grades, the finding indicates higher levels of learning engagement when compared to non-ICT-based instruction. The research also indicates improvements in academic achievement in Reading, Language Arts, and Mathematics. The academic improvements can be considered noteworthy, yet this project's full potential may not have been realized due to infrastructure challenges. McKenna [35] also notes infrastructure as an essential component of the project, which experiences some shortfalls in ICT integration due to limited wireless infrastructure. The infrastructure challenges were so significant that instructors had to coordinate ICT-based instruction between classrooms to avoid using iPads simultaneously. The study underscores the important role of infrastructure in determining access and use even when ICT-based solutions are available to students.

The global pandemic illustrated the importance of ICT infrastructure in education as millions of children within the United States and elsewhere around the globe were mandated to remote learning. While many schools had the resources to distribute laptops and other technology devices to students, a variety of technological challenges emerged elsewhere that demonstrated that developed countries such as the United States still face challenges at all levels of the digital divide as identified by Hohlfeld [16]. A survey by Education Week, a highly regarded resource for K-12 education news in the United States, indicated that many students had access to the internet and technology devices to support remote learning [36]. The survey also notes that many students had no internet access or technology devices to support remote learning [36]. The absence of essential ICT resources during the pandemic poses both short and long-term challenges in learning outcomes and achievement in digital literacy. It also illustrates that the designation of a "developed" country does not preclude students and schools from facing similar challenges compared to their developing nation counterparts. 


\subsection{Infrastructure \& ICT- Liberia}

In 2003, the 14-year long civil war in Liberia ended, leaving much of the country, including critical infrastructures, devastated. Schools and corresponding structures were destroyed, and the longevity of the civil war resulted in high illiteracy rates as a substantial percentage of the population was unable to attend school [37]. Describing such conditions that ICT integration needed to overcome in Liberia and the structurally related challenges, Williams \& Bentrova [38] note that the civil war and Ebola outbreak have resulted in "fragility and structural weaknesses" of the education system, which is categorized by shortages of schools, teachers, and essential school supplies in the country (p. 30). To provide further context, Wafula [39] observed that many countries experience obstacles to ICT integration due to limited or no electricity access. As a result, the utilization of computers, laptops, and other electronic devices has become nearly impossible due to the inability to charge and power the ICT devices. These issues, particularly in rural areas, are further compounded by internet access limitations, which serve as a key component of ICT infrastructure.

Despite the challenges of civil war, Ebola, and COVID-19 spread, Liberia continues to demonstrate a concerted effort to enhance the ICT infrastructure in the country with targeted efforts within the education sector. The Liberia Information and Communications Technology (ICT) 2019-2024 plan is a comprehensive document that aims to address many of the country's critical digital needs. Within education, the policy seeks to survey current internet access levels for all schools, expand internet availability by $20 \%$, and identify critical ICT skills needed to better prepare teachers for the ever-changing technological demands of the $21^{\text {st }}$ century [40]. Liberia's commitment to enhancing the ICT infrastructure is also demonstrated through the country's Pro-Poor Agenda for Prosperity and Development (PAPD) framework. The five-year plan places critical importance on technology access and education to reduce poverty [41].

Liberia's efforts to expand ICT infrastructure and internet access in education extend beyond policy development. The country has also leveraged innovative strategies which address the critical challenges with limited ICT infrastructure. One such strategy is the Internet Backpack which was piloted in 2018 and was designed to bridge the current internet access gap for the billions of individuals without access to this important resource [42]. The country is also leveraging mobile phones and learning (m-learning). More specifically, Worldreader, a non-profit organization dedicated to improving literacy worldwide, has partnered with one of the primary mobile phone companies (Orange Liberia) to preinstall the app on mobile phones [43]. The non-profit organization provides a vastly discounted library of educational resources for use for teachers and students.

\subsection{Teachers \& ICT- United States}

Various factors determine the level of successful experiences related to expanding access to and use of ICT among underserved populations. Core to these factors is the "qualifications, skills, knowledge, and appropriate teachers' attitudes" [44, p. 416]. Teachers' ICT competence, which includes qualifications, skills, knowledge, and attitudes, is core to addressing the current digital divide. The literature related to teachers' role in the integration and use of ICT can be categorized into two areas: (1) the importance of teacher ICT competence and (2) higher levels of student achievement to teacher ICT competence. Studies show that both areas are inextricably linked, illustrating the pivotal role educators play in addressing the research question.

For ICT integration to help underserved populations realize greater access and use of these resources, a concerted effort acknowledging the role of teachers is required. Banister \& Reinhart [45] investigated students' essential needs related to equity and student achievement in the United 
States. Students within target schools that were predominantly minorities with low socioeconomic backgrounds demonstrated limited availability of key resources for successful learning compared to other middle-school students. The authors investigated whether ongoing teacher professional development training successfully closed achievement and technology resource gaps for underserved students. Their findings conclude that investments in ongoing, quality professional development training can address the digital divide, particularly in schools with high marginalized student populations.

"Teacher training in the United States is one of the most cited reasons for lack of technology implementation in the classroom" (Birch as cited in Ruggiero \& Mong [46, p. 163]). Investigating the misalignment of technology integration practices with teaching styles in the Midwest region of the United States, Ruggiero \& Mong [46] found that technology use was prevalent in the classroom, with PowerPoint being the most widely used resource. Teachers also suggested that the most beneficial ICT training is contextually based in the classrooms. The study concludes that barriers to integration exist and must be overcome for integration to be successful. These barriers were categorized as both internal (teacher perceptions, peer support) and external (infrastructure, training). The authors advocate for teacher technology training that is content-specific and contextrelevant to provide educators with the optimal learning experiences to support underserved students better.

\subsection{Teachers \& ICT- Liberia}

The SDG\#4 highlights the need to increase quality teachers through professional development, particularly in developing countries. Expanding upon this goal, the critical role of teachers in facilitating the expansion of access and use of ICT for underserved populations is well-illustrated throughout the literature. Currently, Liberia faces challenges with attracting and retaining quality teachers. While exploring the current state of teacher education in Liberia, Upadhyay \& Taddese [18] identify a series of barriers facing teachers in Liberia, including inadequate training and support. The authors note that approximately only $50 \%$ of educators in Liberia possess the necessary skills and training to teach at the appropriate grade level effectively [18]. More specifically, Ginsburg et al. [47] researched teacher qualifications in Liberia and found that just $68.6 \%$ of individuals had obtained the required C-Certification. Of critical importance is that the authors noted the variation in this certification occurred by location, with some areas having only $25 \%$ of teachers meet the country teaching standards.

The lack of qualified teachers is not unique to Liberia. A report conducted by UNESCO [48] examined teacher pipelines in Sub-Saharan African countries. It noted that many areas experienced teacher shortages due to increasing policy focusing on primary education enrollment. There is also considerable underrepresentation of women in the teacher workforce. The limited teacher qualifications serve as a critical barrier in the successful deployment and use of ICT in Liberia. While exploring the limited number of women in the Liberian teacher workforce, Stromquist et al. [49] identify cultural barriers to women obtaining an education as a key reason for the current underrepresentation in this important field.

Nagbe [50] observes that teacher shortages in Liberia date back to the 1800s. However, the country has implemented various strategies to address this critical challenge that ultimately influences the ability to introduce and implement ICT into primary education successfully. In 2006, the Liberian government dedicated resources to increasing teacher salaries and providing expanded teacher training [50]. One year later, the Liberian Ministry of Education, in conjunction with USAID, launched the Liberia Teacher Training Program (LTTP) with the primary objective of restoring key teacher training institutes (TTI) that become inoperable during the civil war [51]. Underscoring the important role that teachers play in transforming the Liberian education system, Fashina [52] 
International Journal of Education (IJE) Vol.9, No.2, June 2021

suggests strategies such as greater collaboration among schools, the establishment of teacher professional development networks, and similar innovative approaches to teaching.

\subsection{ICT \& Student Exposure- United States}

The widespread availability of ICT, coupled with an increasing reliance on technology in education, has fueled resource allocation and strategies adopted to create greater exposure for students. Programs such as 1:1, which provides one laptop or similar device to one child, have become increasingly popular to address future education demands and ideally bridge the current ICT inequities for underserved populations.

Ritzhaupt et al. [53] leveraged their research in Florida, USA, to investigate the use of ICT resources by students, the efficiency of this use, and the relationship between ICT and student selfempowerment. The research explored this question within the context of gender, ethnicity, and socioeconomic status. Key to the findings was confirming the digital divide based on gender, ethnicity, and socioeconomics. More specifically, higher socioeconomic, female, and White students performed better than their peers on the literacy assessment. The results relating to females are particularly interesting as it is contrary to other research findings suggesting that males are more technology literate and use it more. The study implies that girls may demonstrate greater proficiency, as well. The study also aligns with prior research on students with low socioeconomic status and the digital divide, as this group of students performed lower than their peers. The study concludes that greater exposure to ICT for disadvantaged students is required to bridge the current digital divide and encourages the use of after-school programs as a possible way to provide these learning experiences. Recognizing the comprehensive nature of expanding access to and use of ICT for underserved populations, the research also advocates for local-level partnerships that promote ICT "learning experiences for students, families and community members at large" [53, p. 300].

Adequate access to ICT is an essential precursor for effective learning to be realized within K-8 educational environments for underserved populations. This need for access is evidenced in the work by Vigdor et al. [24], who, through a longitudinal study, examined nearly one million students in grades 5-8 to determine if access to at-home computers and the internet improved student achievement. At the core of this research was a confirmation of the digital divide related to home computer access based on socioeconomic status (SES). The results indicate that the "across student models" show an overall improvement in student achievement scores based on home computer access. However, the within-student data showed no improvement in test scores based on the availability of computers at home. The study showed that students who are afforded home computer access in grades 5-8 show a decline in performance on end-of-year exams. The research concludes mixed results regarding the impact of home-based computers. These results suggest that initiatives that provide greater exposure to technology must be targeted and well-supervised to ensure productivity of learning-based tasks.

Highlighting the promises and pitfalls of greater technology exposure among underserved populations, Jackson et al. [54] investigated the limited research exploring the relationships between how often and to what extent the internet is used based on race and gender for children. The results indicate that White children had used ICT longer than African American children, and males have used computers longer than females. African American males use computers less than any other group. However, African American females used the internet more than any other group. Males played video games more than females. Females used cell phones more than males, and African American children used mobile phones at the highest rates of all groups. Parent income and education were also strong predictors of ICT use for children. In addition, students who had used ICT longer also demonstrated better academic performance. The authors conclude 
that a new digital divide is being cultivated at the intersection of race and gender. This new divide is supported by the idea that African American females are beginning to gain ground in ICT use and, in some cases, surpass White students. At the same time, African American males continue to lag behind their peers. As such, the study recommends interventions targeting African American males focusing on ICT exposure and use.

Ahn et al. [55] also investigated the critical role of expended technology exposure in an urban Washington D.C. school district within the context of an online math game called First in Math (FIM). The results show the more effective use of FIM among elementary students as compared to middle school students. In addition, students of color leveraged FIM more often than their peers. Students with higher academic performance indicators also used FIM more often than their peers. Females students also spent less time on FIM when compared to males. Increased use of FIM was also positive for lower-performing school environments. Students of color, except for Asian students, scored lower on the end-of-year assessment. The study concludes that a positive relationship exists with the increased use of FIM and end-of-year assessments. The results also indicate the potential of technology in improving student achievement. Ultimately, the study demonstrates positive results that should be considered when discussing ways to effectively integrate technology into learning experiences, particularly for underserved populations.

\subsection{ICT \& Student Exposure- Liberia}

Student exposure to ICT is essential for enhancing access to and use of ICT, particularly for marginalized populations. The onset of COVID-19 underscored the importance of technology within the education sector and vividly illustrated the digital divide. In response to the unanticipated remote learning, Liberia leveraged existing technology in the form of radios to deliver education during this unprecedented time. The Rising Academy Network, one of the fastest-growing companies focused on quality education in Africa, developed Rising on Air, a 20- week program consisting of various educational resources designed to further education during the global pandemic [56]. Similarly, the country leveraged additional partnerships such as the Rumie Initiative to provide greater ICT exposure to students. The Rumie Initiative is supported by a Toronto-based organization aiming to provide low-cost technology with educational resources to students in developing countries [57]. The Rumie Initiative builds upon the lessons learned from One Laptop Per Child initiatives by leveraging greater local support and designing technology that does not rely on internet access as a precursor to education delivery.

One of the most substantial strategies to improve education, expand technology access, and enhance ICT use among students is the Liberia Education Advancement Program (LEAP) which outsourced education to various partners. In the 2016-17 academic year, the Liberian government partnered with Bangladesh Rural Advancement Committee (BRAC), Bridge International Academies (BIA), Youth Movement for Collective Action (Liberian Youth Network), More than Me, Omega, Rising Academies, Stella Maris, and Street Child [58]. Cooperatively, these organizations provided oversight to 93 schools and supported approximately 27,000 students. The pilot program represented approximately $3.4 \%$ of the total public primary schools and $8.6 \%$ of the total students [59]. Although the pilot results were varied, some findings indicate greater than learning improved by nearly $60 \%$ [60]. Ultimately, the initiative demonstrates the country's continued commitment to quality education, leveraging key partnerships and providing greater ICT opportunities to students. 


\section{Conclusion}

Several conclusions can be made as a result of this comparative literature review. First, ICT inequities continue to exist for underserved populations based on gender, ethnicity, and socioeconomics, regardless of geography. Second, several factors continuously emerged as key areas that facilitate access to and use of ICT among underserved K-8 populations in the United States and Liberia. These factors are infrastructural support, including power supply, competent teachers, and ICT exposure for students. Third, ICT is essential in the ability to deliver quality education. These conclusions demonstrate that the key factors facilitating access to and use of ICT for underserved populations are not unique to developed or developing nations. Instead, the conclusions are recurring themes related to the digital divide within education that span across socioeconomic conditions, gender, race, and schooling system exists in both countries.

The literature related to infrastructure documents a critical need, particularly in rural areas of the United States and universally in Liberia. The infrastructure research speaks directly to the need for hardware and software and focuses on reliable internet connectivity. The research conclusions also suggest key infrastructure needs related to physical components such as power supply and electricity. With considerable attention focusing on providing access to technology, infrastructure is fundamental to understanding and addressing the current gaps in ICT use and access for underserved populations. After decades of technological integration within education, resource constraints continue to be one of the most significant barriers impacting students' and teachers' use of ICT. In support of this trend, Carver [9] noted that "equipment availability, more than any other factor, seemed to have the greatest impact on whether the technology was incorporated into classroom instruction" (p. 115).

Limited infrastructure represents a significant challenge to technology deployment and use in educational systems. This challenge becomes particularly important when considering the existing inequities among the underserved populations in both countries. Arguably, infrastructure can, in many ways, be viewed as the most important factor influencing ICT access and use among underserved populations as it is the foundation for the realization of technology in education. Without proper infrastructure, no level of ICT can be adopted or fully realized. It is imperative that ideologies regarding integrating ICT, particularly for underserved populations, thoroughly and thoughtfully consider the role of infrastructural support in this fundamental process. The literature is evident in the function and critical aspect of infrastructural support, and there are multiple examples of both successes and failures predicated on the status of infrastructure within the learning environment. This also suggests that greater resources may need to be allocated to this important component if ICT equity is to be achieved. These resources must be allocated to the full range of infrastructure needs in alignment with the ICT-related and structural-related areas identified throughout the literature review. Further, a concentrated effort must be placed on internet connectivity and stability so that all students are afforded equitable opportunities to leverage ICT and the vast knowledge that accompanies ICT access via internet usage.

The research related to educators stresses the critical role teachers play in ICT access and use among underserved students. Within the United States, teachers' professional development regarding the integration and use of ICT is paramount to effectively supporting marginalized students. Key to this support and training is ICT-related knowledge, skills, qualifications, and attitudes. Limitations in knowledge, skills, pedagogy, and classroom management related to technology represent essential barriers to effective technology integration [61]. In Liberia, continued effort to produce and retain qualified teachers represents an essential step before a 
more definitive focus on ICT integration in the classroom to improve improved learning can be prioritized.

As critical influencers of ICT access and use for underserved populations, the literature review also suggests that greater efforts be geared towards ensuring that educators have the maximum capacity to leverage ICT. The literature also provides insights into the important role that teachers play and provides examples demonstrating the promise and pitfalls of ICT, particularly among underserved populations when teachers are ill-prepared to leverage ICT resources within the classroom. There is a tremendous spectrum of ICT competence among teachers that must be better addressed through training and other avenues of professional development and capacity building if the current inequities are to be minimized and ultimately eliminated.

The research is also extensive in identifying programs that provide greater ICT exposure for underserved students. Studies also demonstrate that well-planned, targeted, and supervised intervention programs are key to bridging the current ICT divides for this population. As such programs gain popularity, tremendous potential exists in closing the ICT gap. Further, many of the initiatives targeting underserved populations show demonstrated results in student engagement with ICT and improved achievement outcomes. Ultimately, greater exposure to ICT, particularly for students, furthers the SDGs agenda of providing quality education. Initiatives such as those highlighted in the literature review improve the digital literacy of both students and teachers, which will be fundamental in closing current technological gaps in education.

Programs and strategies aimed at providing greater ICT exposure hold tremendous promise. As ICT, particularly computers, laptops, and other electronic devices, become more affordable, the potential for greater access can be realized. Literature related to expanded ICT exposure for underserved populations is promising and has demonstrated the potential that technology holds and not just for those with greater resources and affluence. On a cautionary note, to realize the maximum benefit of technology exposure for underserved populations, efforts must be taken to ensure that technology is not just deployed for "technology's sake." Instead, clear and measurable outcomes must be developed to ensure that technology exposure does not generate further challenges for the already disadvantaged populations but rather serves as an effective means towards the end, which is quality education.

Despite the tremendous and continued efforts towards integrating ICT in education, inequities still prevail. This comparative literature review documents examples of key populations with limited access to ICT. Further, for those underserved populations with access to ICT, additional barriers still exist. Even more profound is that these issues are not geographically bound, impacting both the United States and Liberia alike. This comparative study suggests the challenges of ICT inequities are prevalent, although with varying degrees in each country, regardless of their developed or developing country status. As such, ICT inequities must be viewed as a global imperative if quality access to education for all is to be realized.

\subsection{Future Considerations \& Recommendations}

Collectively, the research question and subsequent literature review indicate that infrastructure, the role of teachers, and technology exposure are key factors that facilitate access to and use of ICT for underserved K-8 populations in the United States and Liberia and are necessary contributors to improve student achievement. The three factors identified as facilitating access to and use of ICT among underserved K-8 populations are essential considerations given the occurrences in both local contexts (the United States and Liberia). The commonality between the two countries suggests that these factors may warrant global consideration when discussing ICT access and use among marginalized populations. The factors presented within the literature review also suggest 
International Journal of Education (IJE) Vol.9, No.2, June 2021

interconnectivity, which means that these areas should be explored both independently and in conjunction with one another to truly understand the impact and promise of improving ICT access and use for underserved $\mathrm{K}-8$ populations.

The factors presented also indicate a potential hierarchy of importance. Infrastructural support may represent the most critical factor as ICT integration is not possible with insufficient frameworks. Of equal importance is teacher support so that those facilitating the use of the ICT are well-equipped to understand their roles and guide students' learning accordingly. Technology exposure for students can then become possible and impactful once the other two factors have been addressed. Finally, innovation is present at all three levels of these factors influencing how we think about ICT integration, teacher support, and technology exposure for students. The factors presented also provide a broad blueprint of key areas tailored to the uniqueness of each ICT context and underserved population. This eliminates the "one-size-fits-all" model, which is often ineffective. Collectively, these factors are important and, if implemented effectively, can improve student experiences with ICT and enable them to have better academic achievement.

\section{ACKNOWLEDGMENTS}

The authors appreciate the School for the Future of Innovation in Society and the College of Global Futures for supporting this work. 


\section{REFERENCES}

[1] United Nations (2020) Quality Education: Why it Matters. Retrieved November 1, 2020, from: https://www.un.org/sustainabledevelopment/wp-content/uploads/2017/02/4_Why-It-Matters-2020.pdf

[2] Fu, Jo. (2013) "Complexity of ICT in education: A critical literature review and its implications," International Journal of Education and Development Using ICT, Vol. 9, No. 1, pp. 112-125. Retrieved November 1, 2020, from: https://www.learntechlib.org/p/111900/

[3] Waydon, Emmanuel Boone, Ying, Liu \& Ketter, Barbara L. (2016) "Free and compulsory primary education policy in Liberia: Gap between promise and actual performance," Education Research International, Vol. 5, No. 1, pp. 8-24. Retrieved May 1, 2021, from: http://erint.savap.org.pk/PDF/Vol.5.1/ERInt.2016-5.1-02.pdf

[4] Bray, Mark \& Thomas, R. Murray (1995) "Levels of comparison in educational studies: Different insights from different literatures and the value of multilevel analyses", Harvard Educational Review, Vol. 65, No. 3, pp. 472-491. Retrieved November 1, 2020, from: https://www-jstororg.ezproxy1.lib.asu.edu/stable/1188395?seq=1\#metadata_info_tab_contents

[5] Kumar, Raju. (2008) "Convergence of ICT and education”, World Academy of Science, Engineering and Technology, Vol. 40, pp. 556-559. Retrieved June 30, 2021, from: https://citeseerx.ist.psu.edu/viewdoc/download?doi=10.1.1.193.2558\&rep=rep1\&type=pdf

[6] Escueta, Maya, Quan, Vincent, Nickow, Andre Joshua \& Oreopoulos, Philip (2017) Education Technology: An Evidence-Based Review, National Bureau of Economic Research (No. w23744). Retrieved May 30, 2020, from: https:/www.nber.org/system/files/ working_papers/w23744/ w23744.pdf

[7] Alliance for Affordable Internet (2020) The Internet is Unaffordable in Liberia: Action is Needed to 'SET' the Agenda for Positive Change. Retrieved November 30, 2020, from: https://a4ai.org/theinternet-is-unaffordable-in-Liberia-action-is-needed-to-set-the-agenda-for-positive-change/

[8] De Witte, Kristof \& Rogge, Nicky (2014) "Does ICT matter for effectiveness and efficiency in mathematics education?", Computers \& Education, Vol. 75, No. C, pp. 173-184. Retrieved June 30, 2021, from: https://doi.org/10.1016/j.compedu.2014.02.012

[9] Carver, Lin B. (2016) "Teacher perception of barriers and benefits in K-12 technology usage", Turkish Online Journal of Educational Technology - TOJET, Vol. 15, No. 1, pp. 110-116. Retrieved June 30, 2021, from: https://files.eric.ed.gov/fulltext/EJ1086185.pdf

[10] Warschauer, Mark (2008) "Laptops and literacy: A multi-site case study”, Pedagogies: an International Journal, Vol. 3, No. 1, pp. 52-67. Retrieved June 30, 2021, from: http://education.uci.edu/uploads/7/2/7/6/72769947/ll-pedagogies.pdf 
[11] Ali, Syed M. (2013) "Challenges and benefits of implementing tablets in classroom for e-learning in a K-12 education environment-case study of a School in the United Arab Emirates", Research Inventory: International Journal of Engineering and Science, Vol. 3, No. 4, pp. 39-42. Retrieved June 30. 2021, from: https://www.academia.edu/download/31713235/G034039042.pdf

[12] Perrotta, Carlo (2013) "Do school-level factors influence the educational benefits of digital technology? A critical analysis of teachers' perceptions", British Journal of Educational Technology, Vol. 44, No. 2, pp. 314-327. Retrieved June 30, 2021, from: https://core.ac.uk/download/pdf/30269894.pdf

[13] Mossey, Sean \& Manoharan, Aroon P. (2019) "The digital divide", E-Government and Information Technology Management: Concepts and Best Practices, Vol. 203, Melvin \& Leigh.

[14] Wei, Lu \& Hindman, Douglas B. (2011) "Does the digital divide matter more? Comparing the effects of new media and old media use on the education-based knowledge gap", Mass Communication and Society, Vol. 14, No. 2, pp. 216-235. Retrieved June 30, 2021, from: https://www.tandfonline.com/doi/pdf/10.1080/15205431003642707?casa_token=hVvpxPmzyQUAA AAA:_UL15cPitUAKKG8Cnc_zR73na4sDo3Q9g6dXUidZRjnIT0N6CnpkPN4EBhnZe297gWimsy M1muFkuQ

[15] Van Dijk, JAGM (2006) "Digital divide research, achievements and shortcomings", Poetics, Vol. 34, No. 4-5, pp. 221-235. Retrieved June 30, 2021, from: https://ris.utwente.nl/ws/portalfiles/portal/6461579/Dijk06digital.pdf

[16] Hohlfeld, Tina N., Ritzhaupt, Albert D., Barron, Ann E. \& Kemker, Kate (2008) "Examining the digital divide in K-12 public schools: Four-year trends for supporting ICT literacy in Florida", Computers \& Education, Vol. 51, No. 4, pp. 1648-1663. Retrieved June 30, 2021, from: https://doi.org/10.1016/j.compedu.2008.04.002

[17] Selwyn, Neil (2004) "Reconsidering political and popular understandings of the digital divide", New Media \& Society, Vol. 6, No. 3, pp. 341-362. Retrieved June 30, 2021, from: http://citeseerx.ist.psu.edu/viewdoc/download?doi=10.1.1.889.4484\&rep=rep1\&type=pdf

[18] Upadhyay, Arjun \& Taddese, Abeba (2020) EdTech in Liberia: A Rapid Scan. EdTech Hub. $\begin{array}{llll}\text { Retrieved June } 30, & \text { from: }\end{array}$ https://docs.edtechhub.org/lib/2HM2SBVM/download/WVKF8PZ8/EdTech\%20in\%20Liberia_\%20 A\%20Rapid\%20Scan\%20\%28DOI_\%2010.5281_zenodo.3830951\%29.pdf

[19] Reinhart, Julie M., Thomas, Earl \& Toriskie, Jeanne M. (2011) "K- 12 teachers: Technology use and the second-level digital divide", Journal of Instructional Psychology, Vol. 38, No. 3/4, pp. 181-193. Retrieved June 30, 2021, from: https://web.b.ebscohost.com/ehost/ pdfviewer/pdfviewer?vid=0\&sid=3d3e6cd2-cc1a-40c3-9556-fc184e45f631\%40sessionmgr102

[20] Osborne, Jennifer H. \& Morgan, Hani (2016) "Focus on Technology: Alleviating the digital divide in the United States", Childhood Education, Vol. 254. Retrieved June 30, 2021, from: https://doi.org/10. 1080/00094056.2016.1180931

[21] Van Deursen, Alexander J.A.M. \& Helsper, Ellen J. (2015) "The third-level digital divide: Who benefits most from being online?" Communication and Information Technologies Annual, Emerald Group Publishing Limited. Retrieved June 30, 2021, from: https://doi.org/10.1108/S2050206020150000010002

[22] OECD (2000) Learning to Bridge the Digital Divide. Retrieved June 30, 2021, from: https://www.oecd.org/site/schoolingfortomorrowknowledgebase/themes/ict/emergingtrendsandissuest henatureofthedigitaldivideinlearning.htm

[23] Wanyonyi, Khisa J. (2014) Delivering Equitable and Quality Education to Remote Kenya Using ICT. $\begin{array}{llll}\text { Retrieved June } & 30, & \text { from: }\end{array}$ https://citeseerx.ist.psu.edu/viewdoc/download?doi=10.1.1.428.5723\&rep=rep1\&type=pdf

[24] Vigdor, Jacob L. \& Ladd, Helen F. (2014) "Scaling the digital divide: Home computer technology and student achievement”, Economic Inquiry, Vol. 52, No. 3, pp. 1103-1119. Retrieved June 30, 2021, from: https://onlinelibrary.wiley.com/doi/pdf/10.1111/ecin.12089

[25] Boone, Michael, Hendricks, M. LaVelle \& Waller, Rusty. (2014) "Closing the digital divide and its impact on minorities", Global eLearning, Vol. 3, pp. 1-6. Retrieved June 30, 2021, from: http://media.aurak.ac.ae/wp-content/uploads/2016/08/closing-the-digital-divide-geljvol3i1.pdf

[26] Rajapakse, Nadeera (2016) “Amartya Sen's capability approach and education: Enhancing social justice”, Revue LISA / LISA e-Journal, No. vol. XIV-n²1. Retrieved June 30, 2021, from: https://journals.openedition.org/lisa/8913 
[27] Ma, Jennifer, Pender, Matea \& Welch, Meredith (2016) Education Pays 2016: The Benefits of Higher Education for Individuals and Society, College Board. Retrieved June 30, 2021, from: https://files.eric.ed.gov/fulltext/ED572548.pdf

[28] Kim, Sinha (2018) "ICT and the U.N.'s sustainable development goal for education: Using ICT to boost the math performance of immigrant youths in the U.S.", Sustainability, Vol. 10, No. 12, p. 4584. Retrieved June 30, 2021, from: https://www.mdpi.com/2071-1050/10/12/4584

[29] Rashid, Ahmed T. (2016) "Digital inclusion and social inequality: Gender differences in ICT access and use in five developing countries", Gender, Technology and Development, Vol. 20, No. 3, pp. 306332. Retrieved June 30, from: https://www.tandfonline.com/doi/abs/10.1177/0971852416660651

[30] ITU (2019) "Publications" Measuring Digital Development Facts and Figures. Retrieved June 30, 2021, from: https://www.itu.int/en/ITU-D/Statistics/Documents/facts/FactsFigures2019.pdf

[31] UNESCO (2020) Startling Digital Divides in Distance Learning Emerge. Retrieved June 30, 2021, from: https://en.unesco.org/news/startling-digital-divides-distance-learning-emerge

[32] United Nations ESCAP (2020) Technology and Inequalities. Retrieved June 30, 2021, from: https://www.unescap. org/sites/default/files/06Chapter4.pdf

[33] Kennedy, Mary M. (2007) "Defining a literature", Educational Researcher, Vol. 36, No. 3, pp. 139147. Retrieved June 30, from: https://www.cedu.niu.edu/ walker/research/AERA\%20Literature.pdf

[34] Warschauer, Mark \& Matuchniak, Tina (2010) "New technology and digital worlds: Analyzing evidence of equity in access, use, and outcomes", Review of Research in Education, Vol. 34, No. 1, pp. 179-225. Retrieved June 30, 2021, from: http://education.uci.edu/uploads /7/2/7/6/72769947/equity.pdf

[35] McKenna, Corey (2012) "There's an app for that: How two elementary classrooms used iPads to enhance student learning and achievement", Education, Vol. 2, No. 5, pp. 136-142. Retrieved June 30, 2021, from: http://citeseerx.ist.psu.edu/viewdoc/download?doi=10.1.1.1081.3446\&rep=rep1\&type=pdf

[36] Lieberman, Mark (2021) "Most students now have home Internet access. But what About the ones who don't?", Education Week. Retrieved June 30, 2021, from: https://www.edweek.org/technology/most-students-now-have-home-internet-access-but-what-aboutthe-ones-who-don't/2021/04

[37] Williams, James (2011) "Education and reconstruction in post-conflict Liberia", Journal of International Cooperation Studies, Vol. 18, No. 3, pp. 55-79. Retrieved June 30, 2021, from: http://www.research.kobe-u.ac.jp/gsics-publication/jics/williams_18-3.pdf

[38] Williams, James, Bentrovato, Denise, \& UNESCO International Institute for Educational Planning (IIEP) (2011) Education and Fragility in Liberia. IIEP Publications. Retrieved June 30, 2021, from: https://www.voced.edu.au/content/ngv:48239

[39] Wafula, Stephen (2014) Preparedness of public Primary Schools in the implementation of Laptops project in Kenya; A case of Kimilili Sub County, Bungoma County (Doctoral dissertation). Retrieved June 30, 2021, from: http://erepository.uonbi.ac.ke/handle/11295/74034

[40] Liberian Government (2019) Information Communication Technology (ICT) Policy 2019-2024. Retrieved June 30, 2021, from: https://eliberia.gov.lr/wpcontent/uploads/ApprovedNationalICTPolicy2019-2024Liberia-1.pdf

[41] Liberian Government (2018) Pro-Poor Agenda for Prosperity and Development (PAPD A Five-Year National Development Plan Towards Accelerated, Inclusive, and Sustainable Development. Retrieved June 30, 2021, from: http://liberianconsulatega.com/wp-content/uploads/2017/07/PAPDPro-Poor-Agenda-for-Prosperity-and-Development.pdf

[42] McKnight, Lee, Smith, Danielle, Salas-Castro, Alvaro \& Belli, Luca (2019) "Sustainable development by Internet backpack in the Democratic Republic of the Congo, Liberia and Costa Rica" 2019 IEEE Global Humanitarian Technology Conference (GHTC), pp. 1-7, IEEE Publications. Retrieved June 30, 2021, from: https://ieeexplore.ieee.org/document/9033122

[43] Kwaku, Christina \& Robinson, Jenny P. Creating a Culture of E-reading around the Globe, Universal Education, Brookings. Retrieved June 30, 2021, from: https://www.brookings.edu/wpcontent/uploads/2016/07/FINAL-Worldreader-Case-Study-1.pdf

[44] Bukaliya, Richard \& Mubika, Augustine K. (2011) "Teacher competence in ICT: Implications for computer education in Zimbabwean secondary schools", International Journal of Social Sciences \& 
International Journal of Education (IJE) Vol.9, No.2, June 2021

Education, Vol. 1, No. 4. Retrieved June 30, 2021, from: https://www.ijsse.com/sites/default/files/issues/2011/v1i4/paper\%209/paper\%209.pdf

[45] Banister, Savilla \& Reinhart, Rachel V. (2011) "TPCK for impact: Classroom teaching practices that promote social justice and narrow the digital divide in an urban middle school", Computers in the Schools, Vol. 28, No. 1, pp. 5-26. Retrieved June 30, 2021, from: http://www.bgsu.edu/content/dam/BGSU/education/teaching-and-learning/gear-up/documents/tpckfor-impact.pdf

[46] Ruggiero, Dana \& Mong, Christopher J. (2015) "The teacher technology integration experience: Practice and reflection in the classroom", Journal of Information Technology Education: Research, Vol. 14, 161-178.Retrieved June 30, 2021, from: https://jite.org/documents/Vol14/JITEv14ResearchP161-178Ruggiero0958.pdf

[47] Ginsburg, Mark, Ansari, Noor, Goyee, Oscar N., Hatch, Rachel, Morris, Emmanuel \& Tuowal, Delwlebo (2018) "Where have all the (qualified) teachers gone? Implications for measuring sustainable development goal target 4. C from a study of teacher supply, demand and deployment in Liberia", African Educational Research Journal, Vol. 6, No. 2, pp. 30-47. Retrieved June 30, 2021, from: https://files.eric.ed.gov/fulltext/EJ1208498.pdf

[48] UNESCO (2015) Regional Overview: Sub-Saharan Africa Education for All Global Monitoring Report. Retrieved June 30, 2021, from: https://en.unesco.org/gem-report/regionalresources

[49] Stromquist, Nelly P., Lin, Jing, Corneilse, Carol, Klees, Steven J., Choti, Truphena \& Haugen, Caitlin S. (2013) "Women teachers in Liberia: Social and institutional forces accounting for their underrepresentation", International Journal of Educational Development, Vol. 33, No. 5, pp. 521530. Retrieved June 30, 2021, from: https://doi.org/10.1016/j.ijedudev.2012.08.002

[50] Nagbe, Kili-Moses (2015) Perceptions on Improved Salaries and Free Teacher Education: A Qualitative Study of the Liberian Experience, Northcentral University.

[51] Skovgaard, Sara. (2011) Bridging the post-conflict gap: Capacity development in countries affected by fragility:-a case study of the Accelerated Learning Programme in Liberia (Master's thesis). Retrieved June 30, 2021, from: https://www.duo.uio.no/bitstream/handle/10852/30619/1/BridgingxthexpostconflictxgapCapacityxDevelopmentxinxcountriesxaffectedxbyxfragility.pdf

[52] Fashina, Adebayo A. (2017) "Teacher quality and Liberia's educational system. Arts and Humanities Open Access Journal, Vol. 1, No. 4, pp. 132-133. Retrieved June 30, 2021, from: https://www.researchgate.net/publication/323117151_Teacher_Quality_and_Liberia\%27s_Education al_System

[53] Ritzhaupt, Albert D., Liu, Feng, Dawson, Kara \& Barron, Ann E. (2013) "Differences in student information and communication technology literacy based on socioeconomic status, ethnicity, and gender: Evidence of a digital divide in Florida schools", Journal of Research on Technology in Education, Vol. 45, No. 4, pp. 291-307. Retrieved June 30, 2021, from: https://files.eric.ed.gov/fulltext/EJ1010656.pdf

[54] Jackson, Linda A., Zhao, Yong, Kolenic III, Anthony, Fitzgerald, Hiram E., Harold, Rena \& von Eye, Alexander (2008) "Race, gender, and information technology use: The new digital divide", Cyberpsychology \& Behavior: The Impact of the Internet, Multimedia and Virtual Reality on Behavior and Society, Vol. 11, No. 4, pp. 437-442. Retrieved June 30, 2021, from: https://academics.hamilton.edu/ebs/pdf/NDD.pdf

[55] Ahn, June, Beck, Austin, Rice, John \& Foster, Michelle (2016) "Exploring issues of implementation, equity, and student achievement with educational software in the D.C. public schools", AERA Open, Vol. 2, No. 4. Retrieved June 30, 2021, from: https://journals.sagepub.com/doi/pdf/10.1177/2332858416667726

[56] Lamba, Keya \& Reimers, Fernando (2020) Sierra Leone and Liberia: Rising Academy Network on Air. Retrieved June 30, 2021, from: https://documents1.worldbank.org/curated/en/ 182171599124695876/pdf/Sierra-Leone-and-Liberia-Rising-Academy-Network-on-Air.pdf

[57] Koomar, Saalim, Coflan, Caitlin M. \& Kaye, Tom (2020) "Using EdTech in settings of fragility, conflict, and violence: A curated resource list (EdTech Hub Helpdesk Response No 8)". Retrieved June 30, 2021, from: https://doi.org/10.5281/zenodo

[58] Hook, Tyler (2017) Partnership Schools for Liberia: A Critical Review, Education International. Retrieved June 30, 2021, from: nber.org/system/files/working_papers/w23744/w23744.pdf 
International Journal of Education (IJE) Vol.9, No.2, June 2021

[59] Romero, Mauricio, Sandefur, Justin \& Sandholtz, Wayne A. (2019) Outsourcing Education: Experimental Evidence from Liberia. Retrieved June 30, 2021, from: http://mauricioromero.com/pdfs/papers/PSL_Final.pdf

[60] Edwards, Sophie (2017) Early Results: Did Private Outsourcing Improve Liberia's Schools? Inside Development Education. Retrieved June 30, 2021, from: https://www.devex.com/news/early-resultsdid-private-outsourcing-improve-Liberia-s-schools-90943

[61] Hew, Khe F. \& Brush, Thomas (2007) "Integrating technology into K-12 teaching and learning: Current knowledge gaps and recommendations for future research", Educational Technology Research and Development, Vol. 55, No. 3, pp. 223-252. Retrieved June 30, 2021, from: https://www.jstor.org/stable/30221244

\section{AuTHORS}

Damita Kaloostian is a current $\mathrm{PhD}$ student within the Innovation \& Global Development Doctoral Program in the School for the Future of Innovation in Society at Arizona State University. Her research interests include digital inequities in education with a focus on marginalized populations within the U.S. and Africa.

Nalini Chhetri is the associate director for international initiatives and a clinical associate professor in the School for the Future of Innovation in Society and with the School of Sustainability at Arizona State University. She holds a doctorate in education policy studies with a minor in demography, and an MSc in cytogenetics. Chhetri's research work centers around vulnerable communities in areas of climate impacts, science policy, technology, knowledge systems, gender, and urban sustainability. She works with think-tanks and universities in China, Ghana, India, Nepal, Bangladesh,

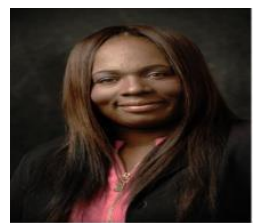
Sierra Leone, and Guyana. 